\title{
Drug Shortage Crisis in US During the 21th Century: Causes, Effects, and Management Strategies
}

\author{
Lixuanyi $\operatorname{Pan}^{1, *}$ \\ ${ }^{1}$ Vassar College, New York, United States, 12604 \\ *Corresponding author. Email: lixuanyi.pan@cheshireacademy.org
}

\begin{abstract}
During the 21th century, drug shortages, in rapidly increasing frequency, posed severe and numerous difficulties to the American health system. Drug shortages are caused by various factors: shortage of raw materials, quality issues, regulatory problems, business and economic issues, and so on. These problems have harmful impacts on patients, health care facilities, federal regulators, and drug distributors mentally, physically, financially, or reputationally. The reason is that doctors have to use substitutive medicine or change the treatment procedures, which may cause safety risks and costly but futile expenditure. People still lack an effective method to solve the drug shortage crisis as it is a complicated and long lasting problem. Fortunately, there are several ways to circumvent or minimize the impact of the crisis. In order to generate a perfect plan to manage drug shortages, health care systems need efficient information-gathering, avid collaborations, and timely communication. The major causes of drug crises are the slack warning system and manufacturing hardships. The author advises the healthcare systems to use wise strategies, such as establishing effective interactions between health systems and sites and identifying alternative drugs or therapeutic equivalents, to navigate through drug shortages. The resources of this essay are from Google Scholar, under the topics of the causes, effects, and managements of drug crises. This paper discusses the causes and effects of drug shortages, and puts forward some suggestions on management strategies.
\end{abstract}

Keywords: drug shortage, FDA, economy, safety, manufacturer.

\section{INTRODUCTION}

Drug shortages are continuous problems in the United States, which captivates the attention of innumerable researchers and governmental officials. Tracked by ASHP and FDA, the frequency of drug shortages is surging during the $21^{\text {th }}$ century, a worrisome phenomenon. According to "Drug Information Service at University of Utah Health Care (UUHC), which partners with the ASHP to manage its drug shortage program", there is "a total of 211 drug shortages in 2010 - the highest number recorded to date in a single year" [1]. "ASHP/UUHC reported 70 in 2006, 129 in 2007, 149 in 2008, and 166 in 2009. For 2011, there have been 210 shortages reported as of September 15. At the time of this writing, 203 drugs were listed on the ASHP/UUHC drug shortage Website and 73 medically necessary drugs were listed on the FDA Website" [1]. The data proves that the number of drug shortages is sharply escalating throughout the 21th century, evoking concerns on the quality of medical treatments. The number of medications in active shortages is still increasing rapidly, "from 60 per week in 2016 to more than 100 in 2018" [2]. The drugs that are in deficit include "injectable antibiotics, such as vanco- mycin and cefazolin; chemotherapeutic agents, such as vincristine and doxorubicin; and anesthetics, such as lidocaine and bupivacaine" [2]. These drugs have been widely used as rudimentary medications in the United States for decades. It is troublesome for surgeons and pharmacists to adapt to this predicament and find effective replacements, so the quality of healthcare will be profoundly inflicted. This paper discusses the causes and effects of drug shortages, and puts forward some suggestions on management strategies.

Since drug crises warrant awareness, many authorities are intervening aggressively and researchers are discussing enthusiastically about the diverse aspects of drug shortages. From 2001 to 2019, "430 papers were charted according to the following categories: causes, impacts on care, health outcomes, costs, management, prevention, and federal government response. Of these, 112 papers considered causes; 199 discussed effects, 158 
considered management strategies, and 140 discussed prevention" [3]. The Drug Shortage Era: A Scoping Review of the Literature 2001-2019 summarizes the articles published during the 21 th century regarding the drug shortage issues. The review extracts the essence from those researches and organizes them to enlighten readers about the areas the United States should probe deeper to solve drug crises. The Drug Shortage Crisis in the United States extensively explains multiple causes and effects of and present solutions to drug shortages. It gives readers a scope for comprehending the mechanism of drug shortages and healthcare systems. In Drug Shortages in the United States: Are Some Prices Too Low, Inmaculada Hernandez focuses on how manufacturing and purchasing concentration of and deficiency of financial incentive to produce generic drugs result drug shortages. Hernandez also points out that the interference and control of FDA can ease the problems. DK Gupta, the author of Drug Shortages in the United States: A Critical Evaluation of Root Causes and the Need for Action, underlines the benefits of altering drug allocation and administration to diminish the damages of drug crises. In order to fully exert and navigate those articles to reduce the effects and occurrences of drug shortages, it is necessary to identify the links between causes, impacts and strategies. This paper explores the relationships between the three cardinal elements. By integrating these elements, it will help readers develop a comprehensive understanding about drug shortages and instruct the audience to evaluate and improve the present remedies of drug crises.

\section{CAUSAL ANALYSIS OF DRUG SHORTAGES}

\subsection{Reckless warning system}

There are many factors that contribute to drug shortages. The first noteworthy factor is the discursive warning systems between FDA, manufacturers, and drug distributors. Because of the desultory warning system, FDA cannot intervene timely into the impending drug shortages, and healthcare facilities are often unconscious of the drug shortage crisis until the inventory is empty. The second factor is the manufacturing difficulties, which can be caused by elements such as transportational hardships, contaminations, or shortages of raw materials.

The loose warning system is currently the most significant cause of drug shortages. On 9 July 201, Barack Obama "signed into law the US Food and Drug Administration (FDA) Safety and Innovation Act" [4], which requires manufacturers to "report possible drug shortages" [4]. However, "the FDASIA does not address every component that contributes to the development of drug shortages" [4]. The legislation merely extends the authority of FDA on drug manipulation, but ignores the fact that drug shortages are caused by diverse factors.
Expanding the power of the FDA will not cease the drug crisis effectively. The act does not offer any valid solution to "how practitioners can adjust to and make up for drug shortages with similar-class drugs" [4], so its perspective is too narrow and it is inadequate to solve the problem. Now, requirements on drug manufacturers are heedlessly performed. Manufacturer will not be penalized if they did not provide notification. Manufacturers are supposed to "give the FDA six months' advance notice only when they plan to stop producing a single- source, medically necessary drug" [1].

However, according to CDER Drug Shortages Staffs, medically necessary drug is "any drug product used to diagnose, treat, or prevent a serious disease or medical condition for which there is no other drug that is judged by CDER medical staff to be an appropriate substitute or there is an inadequate supply of an acceptable alternative as determined by the DSS" [5]. The policy is vague, since FDA simply offers "some fairly broad terms as yardsticks for when pharmaceutical companies would have to provide indications of what appear to be upcoming shortages, and how quickly companies have to communicate with the FDA about them" [6]. As a result of the blurred phrasing, manufacturers habitually do not inform or provide limited information to FDA about an impending drug crisis. An early admonition can be extremely beneficial to the healthcare system, because FDA can work with firms to address the drug shortages in time, "such actions averted 38 shortages during 2010" [1]. On the other hand, drug distributors often provide inconsistent information to the healthcare system about drug inventories. Many distributors also use "just-in-time inventory for budgetary reasons", which means products are received from the suppliers only when they are needed [7]. This method can reduce inventory cost and increase inventory turnovers. However, this management also makes the healthcare system vulnerable, because it requires drug distributors and healthcare facilities to communicate punctually to ensure the supply of drugs. Now, hospitals "are often unaware of drug shortages until it is no longer possible to purchase a product" [1]. The unreliable information and untimely warnings cause many obstacles for pharmacists to prepare for unavoidable drug shortages.

\subsection{Manufacturing difficulties}

Other than the "soft" warning system, the manufacturing difficulties may also cause drug shortages. Factors such as "antiquated equipment, a shift of a company's resources from manufacturing to research and development, and loss of production and compliance personnel" may contribute to manufacturing problems [1]. Obviously, the manufacturing process is affected by multiple elements, including business decisions, technical issues, and the performances of healthcare staff. 
The supply chain of drugs is highly susceptible, which shows its weakness and sensitivity. Pharmaceutical manufacturing includes four main processes: "the synthesis of APIs and inactive excipients, the production of an administrable form, packaging, and labeling" [7]. Pharmaceutical manufacturers "depend on a limited number of API suppliers; any disruption in production of ingredients, such as due to a regulatory concern or a natural disaster, will consequently affect manufacturing" [7]. Also, drug manufacturing is strictly circumscribed by the FDA, as studies show that "more stringent regulations have increased the real U.S. drug development costs by an average of 6 percent per year and have reduced by half the number of new drugs introduced in the United States" [8]. The FDA oversight bridles drug companies from remedying the impending drug shortage crisis opportunely, since companies are under higher economic and working pressure. Drug manufacturers are required to pass through a series of sophisticated and timeconsuming inspections in order to get the permission from the FDA to produce a new drug or open a new production line. According to researchers, "the cost of bringing a new drug to the market to be \$231 million", which underscores the financial burdens of drug manufacturers [8]. Furthermore, drug manufacturers, due to monetary and technological issues, may be incapable of producing sufficient drugs to solve the drug shortage even after they are approved by the FDA. One of the reasons is that manufacturing machines are expensive and elaborate. It is onerous and costly for companies to purchase and install. Most companies "use the same manufacturing equipment for many drug products, so it is difficult to increase production of one product without causing manufacturing shortages and delays for another" [1]. In addition, there are certain medicines, such as sterile parenteral drugs, "demand highly specialized production lines, are expensive to produce, and are typically among the drugs needed to manage mass critical care" [7]. Despite the unaffordability of buying a new machine and opening a specialized production line to many drug manufacturers, "there is often a significant lag between a supply shortfall and a production increase at another facility" [1]. Clearly, setting up production of a drug in short supply is an ineffective and passive way to merely postpone the drug shortage crisis. Another solution is to contract with other manufacturers to make the drug. Nevertheless, antitrust laws, which forbids monopolization and recognizes information sharing as "unilateral bullying", "unfair practices", or "abuse of dominance" [9], may prevent companies from collaborative production. The regulatory constraint may aggravate or accelerate the drug shortages.

\subsection{Shortages of raw materials}

Sometimes, shortages of raw materials provoke manufacturing hardships, which lead to drug crises. The disruption in the supply of bulk in raw materials may cause severe issues "when a primary or sole-source supplier of a raw material delays or discontinues production, affecting multiple manufacturers" [1]. Since many drugs with multiple manufacturers only have one producer of their raw materials, the disruption in the supply of raw materials will have detrimental impacts on the whole drug production chain. The United States is also exceedly dependent on foreign countries to offer drug substances, as " $80 \%$ of the raw materials in the pharmaceuticals sold in the U.S. are imported from abroad. Suppliers could be in Europe, India, or China" [1]. The international transportation of raw materials is liable to accidents and disturbances. Mishaps such as "armed conflicts, political upheaval, trade disputes, animal diseases, and degradation or contamination during transport" can all lead to drug shortages. The distance between the supplying and demanding countries makes the supply chain fragile and brittle. For example, "in 2005, an increase in demand for and a shortage of certain drugs resulted from hurricanes Katrina and Rita" [1]. Natural disaster is an imperative element that affects the availability of drugs.

\section{EFFECTS OF DRUG SHORTAGES}

\subsection{Increased expenditure of healthcare system}

\subsubsection{Increased substitution cost}

Drug shortages, induced by factors listed above, have indelible and traumatic effects on the healthcare system in the United States. One of the major impacts is the increment in hospital expenses. One reason for increasing hospital expenditure is the drug acquisition. Based on the National Survey of The Impact of Drug Shortages in Acute Care Hospitals, healthcare facilities "were forced to purchase it off-contract from their current vendor (75\%), borrow the drug from another institution (75\%), or purchase the drug from an alternative vendor (74\%)" [10]. Premier Healthcare Alliance "after surveying 311 pharmacy experts from 228 hospitals in late 2010, estimated that drug shortages cost hospitals at least \$200 million annually because of the need to purchase more expensive therapeutic substitutes" [1]. The statistics elucidate the economic blow of drug shortages, which coerced hospitals to find replacing medications, is prevalent and devastating. The increased frequency of drug shortages in the United States has fostered the graymarket, "a drug supply channel that is unofficial, unauthorized, or unintended by the original manufacturer" [11]. These unconventional distributors "buy up the remaining stock and then aggressively market it to hospitals, health systems, home care agencies, and physician practices, which are unable to obtain the drug, at 10 to 1,000 times the usual price" [1]. The data confirms that untraditional suppliers earn exorbitant profits during drug shortages, but healthcare facilities will correspondingly confront the mounting 
financial stress. Another severe problem is that alternative suppliers typically "have only a small quantity of product, sometimes only enough for one or two patients. Many do not offer a return or refund on products" [1]. Therefore, the gray market is an unstable and deceptive supplier, which may exacerbate the economic impasse of healthcare systems without solving the drug inventory issue. Healthcare facilities, as consumers, have limited legal rights and protection during these trades. Moreover, the quality of drugs from the untraditional distributors is also questionable. The reason is that drugs from the open market have "no guarantee of proper storage or pedigree, and there is a risk that the product might be counterfeit or compounded"
[1]. Many untraditional distributors exclusively seek extravagant profits during the "once-for-all" trades, so there is no need for them to maintain a permanent relationship with customers. Michael P. Link, M.D., president of the American Society of Clinical Oncology claims that "when you buy gray market drugs it does not have the legacy of the drug. It is not the same quality assurance and you do not know its authenticity" [11]. Consequently, healthcare facilities will face immense uncertainties and maybe high economic loss once swindled by distributors. The drug shortage crisis in the United States from causes, impacts, and management strategies respondents' ratings of existing information sources can be seen in Table 1 .

Table 1. The Drug Shortage Crisis in the United States: Causes, Impacts, and Management Strategies Respondents' Ratings of Existing Information Sources on Drug Shortages

\begin{tabular}{|c|c|c|c|c|c|}
\hline $\begin{array}{c}\text { Rated } \\
\text { Characteristic* }\end{array}$ & $\begin{array}{c}\text { ASHP } \\
\text { Web Site }\end{array}$ & $\begin{array}{c}\text { FDA Web } \\
\text { Site }\end{array}$ & $\begin{array}{c}\text { Wholesaler Web } \\
\text { Site or } \\
\text { Communication }\end{array}$ & $\begin{array}{c}\text { GPO Web Site } \\
\text { or } \\
\text { Communication }\end{array}$ & $\begin{array}{c}\text { Communication With } \\
\text { Manufacturer }\end{array}$ \\
\hline Timeliness & 3.93 & 3.40 & 3.38 & 3.42 & 3.02 \\
\hline $\begin{array}{c}\text { Reason for, } \\
\text { duration of } \\
\text { shortage } \\
\text { provided }\end{array}$ & 3.80 & 3.23 & 2.66 & 3.23 & 2.78 \\
\hline $\begin{array}{c}\text { Suggested } \\
\text { alternatives } \\
\text { provided }\end{array}$ & 3.97 & 2.74 & 1.81 & 3.04 & 1.92 \\
\hline
\end{tabular}

Note: ASHP = American Society of Health-System Pharmacists; GPO = group-purchasing organization.

*Mean rating, based on a 5 -point Likert scale, where $1=$ very poor, $2=$ poor, $3=$ neutral, $4=$ good, and $5=$ very good.

\subsubsection{Increased labor costs}

Other than the costly therapeutic replacements, labor cost is also a tremendously high expenditure, since "the annual labor costs of drug shortages have been estimated to be an additional \$216 million" [1]. Doctors and surgeons are under high workload, because they need to identify alternative API during drug shortages. More staff is often "needed to make operational adjustments required to accommodate product changes" [1]. Based on a survey conducted by ASHP in 2010, "the time health care facility personnel spent on drug shortages has tripled since 2004" [1]. Based on National survey on the effect of oncology drug shortages on cancer care, "approximately $34 \%$ of participants reported that their facilities had dedicated 1000 or more personnel hours to managing oncology drug shortages in 2011; this equates to at least 0.5 full-time equivalent staff resource unit, or approximately 20 hours each week" [12]. As the working hours are extended remarkably and staff numbers escalate dramatically during drug shortages, healthcare facilities are under excessive financial pressure. Pharmacists are in charge of "communicating with manufacturers and wholesalers, providing education to facility personnel on alternative agents, developing or modifying policies or clinical guidelines, and updating electronic databases and medication administration systems" [1]. The innumerable new missions delivered to pharmacists clarify that drug shortages overburden healthcare staff dreadfully. Healthcare systems have to overdraft to accommodate the crisis. Medical treatments are getting more complex and intricate, which require more money to sustain. The quality of these treatments are often compromised, which has many negative impacts on patients physically, another tragic effect of drug shortage.

\subsection{Increased safety risks}

Safety risks correlated with drug shortages closely, since the alternative medications may have side effects or are ineffective. Security issues included "alterations in treatment, inferior treatment, prescription inaccuracies, dispensing errors, administration errors, delayed or denied treatment, prolonged hospitalization, adverse drug interactions, and even death" [13]. These potential hazards demonstrate the destructiveness of drug shortages, and insinuates that drug crises, posing a devastating blow on patients and healthcare systems, are 
still undecipherable. During drug crises, clinical outcomes are usually compromised. The drug crises "among cancer regimens require careful examination" because the therapeutic options can essentially affect "patient quality of life, disease progression" and "survival" [14]. The reason is that healthcare facilities often need to change the therapies completely to address the problems. They may commit "rationing; cancellation of procedures" or applying "alternative treatments that have a worse safety profile, are more expensive, or are more prone to overdoses or medication errors" [1]. Most shortages of cancer drugs will cause fatal issues, because "treatment delay, treatment disruption, lack of therapeutic alternatives for certain indications, and drug substitution of potentially less effective or harmful regimens can adversely affect prognosis and outcomes" [14]. For instance, cytarabine, an effective drug "in treating several forms of leukemia and lymphoma, must be administered as quickly as possible, especially to patients with AML" [1]. During cytarabine shortages, healthcare facilities "had to ration the drug, giving priority to those who they thought most urgently needed it" [1]. Prioritizing patients may retard diseases, and endanger lives during severe drug shortages, especially for diseases that need rapid treatment. Even for drugs that have replacements, the efficacy may be jeopardized. The defects of drug substitution included: "less efficacy; lack of quality evidence supporting efficacy; poor side effects resulting in poor drug tolerance; and lack of clinical experience by staff, clinicians, and pharmacies" [14]. Based on a retrospective study about adult patients with lymphoblastic lymphoma "at a single tertiary medical center using the modified CALGB-10403 protocol with substitution of doxorubicin for daunorubicin", patients who treated with doxorubicin reported "higher toxicity, including longer hospitalization, mucositis, infection, sepsis, and death" [14] compared to those who had daunorubicin. Incontestably, alternative treatment is merely a helpless and reluctant action, which can even elicit more calamities.

\section{CONCLUSION AND SUGGESTIONS}

Based on the resources, understanding the impacts and causes of drug shortages are both important for people to figure out the solution for this crisis. The two main causes are the loose warning system and the manufacturing difficulties. The two major impacts are the increased expenditure and the safety hazards. The author thinks instituting concise regulations and obtaining timely notification is extremely significant for the FDA to step in and rectify the problem. Currently, hospitals believe that "some of the terms the FDA wants to use are ill defined, and that allowing drug manufacturers up to five days to report a shortage after one appears to be imminent gives the companies too much leeway" [6]. Therefore, the regulation should eliminate ambiguous and broad phrases like "life-supporting" or "life- sustaining". Instead, the author proposes that the FDA can generate a list of medicines that fall into the "lifesupporting" category. In addition, the government should enforce the warning system by penalizing the disobedient manufacturers that refuse to provide notification. The author's second proposal is that the healthcare systems should have state-wide resources to share inventory and information. Undeniably, there are several barriers, such as "differing levels of perceived benefit, logistical barriers to drug sharing, sharing of proprietary information, ethical considerations about preferential drug distribution, resource maintenance, updating information into the resource, and interest of the hospital" [15]. In order to ensure the fair distribution of drugs and cohesive collaboration between hospitals, the American government should publish strict laws that forbid venal activities like rat races and stockpiling among healthcare facilities. The government also needs to create an inclusive and handy database, which allows healthcare facilities to update information about drug inventories or resources effectively. Americans still have a long way to go to solve the drug shortage crisis due to its complexity and persistence. By manifesting the main causes and effects of drug shortages, the essay guides readers the directions Americans can research further to assuage or avoid drug shortages properly.

\section{AUTHORS' CONTRIBUTIONS} Pan.

This paper is independently completed by Lixuanyi

\section{ACKNOWLEDGMENTS}

The author cannot express enough thanks to her professor Mr. Axel, teaching assistant Ben Wei, and essay assistant Alisa Wang for this project. They offered me sincere and patient advice and help throughout my work. The author could not complete this paper without the encouragement and financial support from her parents, Fang Li and Zhong Pan. Thank them for allowing her the time and to research and write. The author wants to give them the deepest gratitude.

\section{REFERENCES}

[1] Ventola CL, The Drug Shortage Crisis in the United States: Causes, Impacts, and Management

Strategies, by P T., Nov, 2011.

https://www.ncbi.nlm.nih.gov/pmc/articles/PMC32 78171/

[2] Hernandez Inmaculada, Hershey Tina Batra Donohue Julie M., Drug Shortages in the United States: Are Some Prices Too Low?, JAMA. 2020, vol 323, no 9, pp. 819-820.

[3] Emily L. Tucker \& Yizhou Cao \& Erin R. Fox \& Burgunda V. Sweet, The drug shortage era: a 
scoping Review of the literature 2001-2019, Clin. Pharmacol. Ther., 2020, pp.1-10.

[4] Gupta D K \& Huang S-M, Drug Shortages in the United States: A Critical Evaluation of Root Causes and the Need for Action, Clinical Pharmacology \& Therapeutics, 2013, Vol 93, no 2, pp. 133-135.

[5] U.S. Department of Health and Human Services Food and Drug Administration Center for Drug Evaluation and Research (CDER), Guidance for Industry: Planning for the Effects of High Absenteeism to Ensure Availability of Medically Necessary Drug Products, by OMB Control No. 0910-0675, March, 2011. https://omb.report/icr/2017030910008/doc/72283501.pdf

[6] Barlas Stephen, Manufacturers and hospitals spar over drug shortage reporting: FDA proposal seeks to improve early warning system, $P$ \& $T$ : a peerreviewed journal for formulary management vol. 39, 3 (2014), pp.152-215.

[7] Burry Lisa D. \& Barletta Jeffrey F. \& Williamson David \& Kanji Salmaan \& Maves Ryan C. \& Dichter Jeffrey \& Christian Michael D. \& Geiling James \& Erstad Brian L., It Takes a Village...Contending With Drug Shortages During Disasters, American College of Chest Physicians, Vol 158, Issue 6, December 2020, pp. 2414-2424.

[8] Ward Michael R., Drug Approval Overregulation, by Cato Institute, 1992.

https://www.cato.org/sites/cato.org/files/serials/file s/regulation/1992/10/reg15n4e.html

[9] Steuer Richard M., The Simplicity of Antitrust Law, University of Pennsylvania Journal of Business Law, Vol. 14, No. 2, p. 543, 2012. https://papers.ssrn.com/sol3/papers.cfm?abstract_id $=2163690$

[10] Baumer Amanda M. \& Clark Angela M. \& Witmer David R. \& Geize Shirley B. \& Vermeulen Lee C. \& Deffenbaugh Joseph H., National survey of the impact of drug shortages in acute care hospitals, American Journal of Health-System Pharmacy, Vol 61, Issue 19, 1 October 2004, pp. 2015-2022.

[11] Rosenthal Eric T., The "Gray Market" Raises Concerns about Cost, Safety, and Ethics, JNCI, Vol. 104, Issue 3, pp.168-170.

[12] McBride Ali \& Holle Lisa M. \& Westendorf Colleen \& Sidebottom Margaret \& Griffith Niesha \& Muller Raymond J. \& Hoffman James M., National survey on the effect of oncology drug shortages on cancer care, American Journal of Health-System
Pharmacy, Vol. 70, Issue 7, 1 April 2013, pp. 609617.

[13] Shukar Sundus, Zahoor Fatima, Hayat Khezar, Saeed Amna, Gillani Ali Hassan, Omer Sumaira, Hu Shuchen, Babar Zaheer-Ud-Din, Fang Yu, Yang Caijun, Drug Shortage: Causes, Impact, and Mitigation Strategies, by Front Pharmacol, July 19, 2021.

https://www.ncbi.nlm.nih.gov/pmc/articles/PMC82 99364/

[14] Narissa J. Nonzee \& Thanh Ha Luu, The Drug Shortage Crisis in the United States: Impact on Cancer Pharmaceutical Safety, Springer, vol 171., 2018, pp.75-92.

[15] Emily Chen, Susan Goold, Sam Harrison, Iman Ali, Ibtihal Makki, Stanley S. Kent, Andrew G. Shuman, Drug shortage management: A qualitative assessment of a collaborative approach, by PLoS ONE 16(4), 2021, April 232021. https://journals.plos.org/plosone/article?id=10.1371 /journal.pone. 0243870 